\title{
Design modular tools for social housing: the case of the complex in Rua da Seara by João Álvaro Rocha
}

\author{
J. Cortés Grao ${ }^{1}$, R. Merí de la $\mathrm{Maza}^{2}$ \& A. Díaz Segura ${ }^{1}$ \\ ${ }^{1}$ University CEU Cardenal Herrera, Spain \\ ${ }^{2}$ Universitat Politècnica de València, Spain
}

\begin{abstract}
This study focuses on the architecture of João Álvaro Rocha with the aim to discover the tools and strategies he applied in the design process to reach the highest quality standards in his social housing projects. We will focus on one of the housing estates developed by the architect: the complex in Rua da Seara in Matosinhos, Portugal. We have used diagrams and drawings to illustrate the application of some basic guidelines of architecture which facilitate the construction while reducing costs, basically: repetition, proportion, symmetry and rhythm. These guidelines have been implemented through a series of mechanisms, namely, the systematic use of structural, modular, compositional and building units. In this way, we can demonstrate that these tools help the architects when they face a social housing project.

Keywords: João Álvaro Rocha, social housing, design modular tools, repetition, rhythm, symmetry, structural unit, spatial unit, compositional unit and constructive unit.
\end{abstract}

\section{Objectives}

The architect João Álvaro Rocha is one of the greatest exponents of contemporary social housing in Portugal. His ability to work with some basic architectural guidelines, articulating them in an especially effective manner, gives rise to an architecture characterised by an extraordinary control and precision. Adhering to these guidelines, and applying them consistently, he was able to carry out a large number of high-quality social housing, recognised by the awards received and also by the consideration of his colleagues. As Eduardo Souto de Moura admits: "I 
have no problem in choosing one of the works of Rocha, because it is perhaps the most difficult subject to deal with in this moment: the social housing" [1]. Architect Álvaro Siza, on the other hand, reminded us that "housing is a constant presence in the city and it is always social" [2].

Rocha's design process is based on an exhaustive control of each of the components of the design. His works are exemplary in the use of design tools applied to social housing projects that meet all economic, political and social needs, without losing sight of the intrinsic objectives of a work of architecture. Thus, in an interview on the occasion of an award he received in 2005, Rocha stated the following: "The fact that the award was given to a work of social building, a type of project that is usually underestimated by official institutions and the public because it is not spectacular and thus not mediagenic, has special importance for us. It constitutes a kind of invitation to action, in order to demonstrate that so-called minor projects can, after all, have dignity and be made with the same quality as all the others" [3].

\section{Influences in João Álvaro Rocha's social housing}

Rocha faces the design of social housing buildings with the most universal and logical tools of the profession: geometry and order. Likewise, he incorporated other concepts inherited from his training at the Oporto School of Architecture such as the value of construction and the care for the place. Rocha was consistent in his professional practice, and valued the application of each of the basic guidelines to be able to reach multiple answers to complex problems. For Eduardo Souto de Moura, Rocha's method of work and his success with social housing are condensed into systematisation: "Many times I wonder how he manages to do that architecture, with the qualities and those prices. I know how he gets them, and it is through systematisation to the limit. Few details so that there is not too much diversification, and great discipline. When there are few details and the amounts increase in geometrical proportion, accordingly, prices fall and allow you to choose better and more expensive materials. Rocha has taken advantage of his opportunities and makes the best social housing, in terms of language, discipline, rigour and quality" [4].

Rocha was able to achieve in his dwellings the highest quality with the lowest construction cost through an exhaustive control of every element and by reducing the complexity of detailing to the minimum. In his social housing, he aimed at achieving the qualities that the architect Fernando Távora appreciated in popular housing: "The popular house gives us great lessons when it is properly studied because it is more functional and less extravagant, in a word, is the one that is more in line with the new aims".

By comparing his social housing with similar works of Mies van der Rohe or Le Corbusier, some obvious similarities arise. The systematisation based on the controlled use of a minimum number of details, reminds us of Mies' principles of action. Accordingly, in his design process, the details are standardised and the construction elements are typified, in a search for the ideal social housing design. 
In essence, all these principles rely on a Platonic idea of order. Basic guidelines are for the architect equivalent to notes and keys for the musician.

\section{Housing estate in Rua da Seara}

This complex is located in the city of Matosinhos, in the periphery of the Grande Porto conurbation (Figure 1). The context is the key: the project is located in an urban area of low-rise housing with sloped green zones and also forms a boundary with the surrounding network of roads. Therefore, the design of the housing estate had to respond to the site conditions. Rocha raised a series of linear blocks perpendicularly arranged to the street, separated by a distance that facilitates an adequate permeability towards the back green zones. Both the orientation and the slope of the terrain favour this arrangement of the blocks, with a height that corresponds to the density of the area.
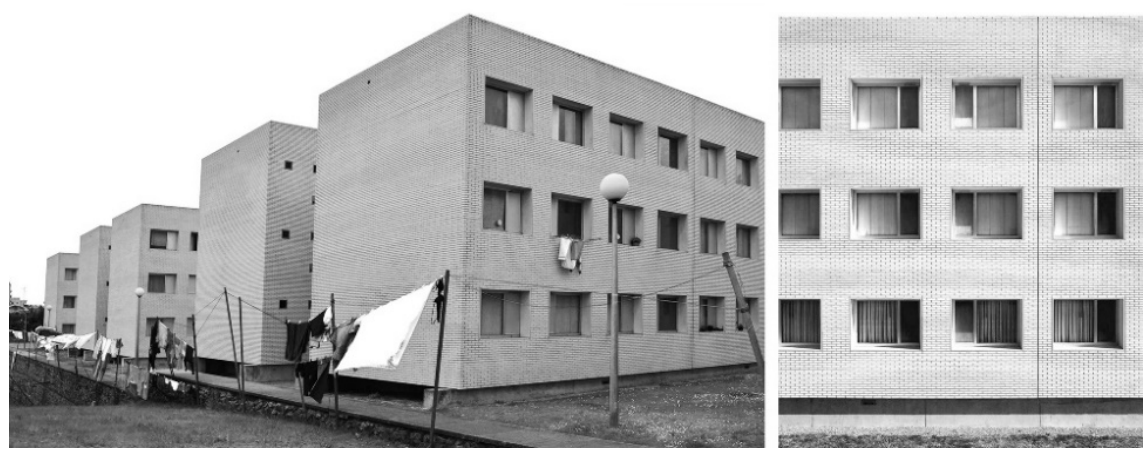

Figure 1: Views of the complex in Rua de Seara by João Álvaro Rocha.

Simple volumes are located in a rhythmic sequence in accordance with the principle of repetition. The blocks are arranged in pairs with in-between spaces of different width: smaller between the single blocks, larger between the pairs. This order is reinforced by the symmetry of the arrangement of the blocks, another basic design mechanism, as shown in the side elevation (Figure 2).

Rocha was aware that there are several factors which make this project unique: orientation, light, uneven terrain, and green areas; these are the keys to bring on variety. In Rocha's words: "Unable to find a perfect and generalizable model, with the ability to respond to all requests, including the place, through the relationship the built object is able to establish with it, eventually it becomes the determinant of the difference, making the object become unique and unrepeatable - just a small ripple on the ground, a slight slope, a loose stone or the shape of the house next door...".

The repetition, the shape and the arrangement of the blocks, remind us of the social housing Unidade Ramalde by Fernando Távora. In that project, Távora built three-story parallelepiped blocks, separated by green stripes, organised in parallel. 
The repetition of these building units gives balance and coherence to the overall complex.

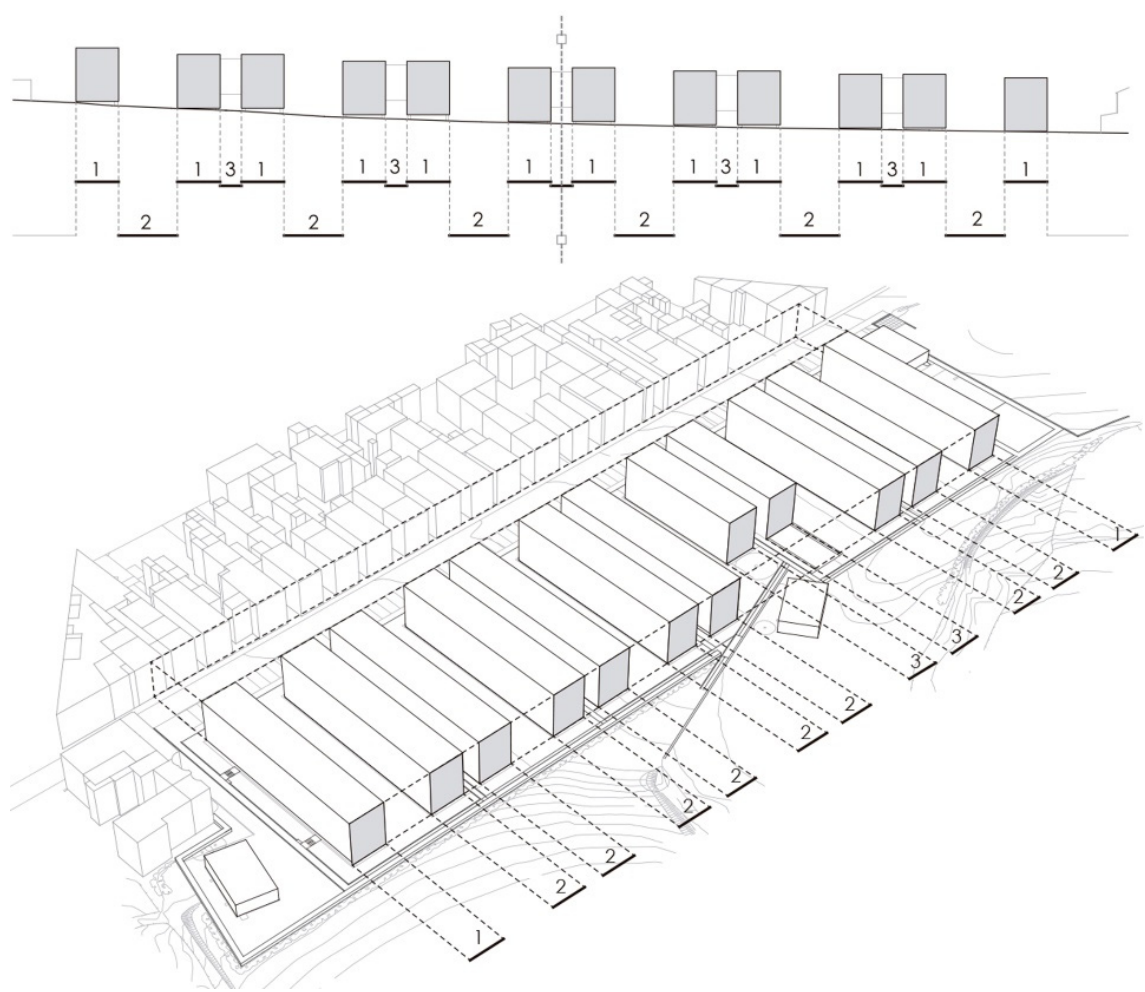

Figure 2: Repetition and rhythm, side elevation and 3D model.

Rocha arranges the openings of both façades of the blocks in a similar way. The repetition of these openings gives rise to a sense of harmony and serenity. The layout of the windows facilitates the identification of each housing unit, as Pozo has contended: "Repetition means better identification of the unit (...)" [5].

Repetition is applied in serial industrialised production to facilitate construction at a lower cost. In Rocha's projects, repetition is a design mechanism to control the relationships (proportion, harmony) between the repeated elements, either blocks, windows or distances. To ensure that repetition does not become banal, the proportion must be controlled from the most basic element to finally taking into account the relationship with the overall ensemble. On the other hand, if the proportion does not take into account the relationship with the human scale or does not respond to the conditions of the setting, it can give an incomprehensible, monotonous and soulless result. This adjustment of the proportion and scale brings beauty to the project, in the same way as occurs in nature. 


\section{Modular design tools}

\subsection{The structural unit}

The arrangement of the support elements in the plan constitutes a basic component of the modular system devised by Rocha: the structural unit. By analysing the floor plan, we can understand the relationships between the support elements with the overall project. The supports are placed at equal intervals, giving rise to a succession which brings about a central axis of symmetry in the block. With this arrangement of the supports, a faster and more efficient construction is achieved.

The structural unit is simple and regular (Figure 3). It is defined by the structural axes of four pillars separated $5.20 \mathrm{~m}$ and $7.15 \mathrm{~m}$ in each direction (we can see one of these units made by the axes $2-3 \times a-b$ ). This unit is repeated up to six times in the plan and generates symmetry from axis number 6 . There is another unit derived from the first one, which is half of the $M$ size. This half unit $(1 / 2 \mathrm{~m})$ is used both to set the vertical communications core and to finish the block in its extremes.
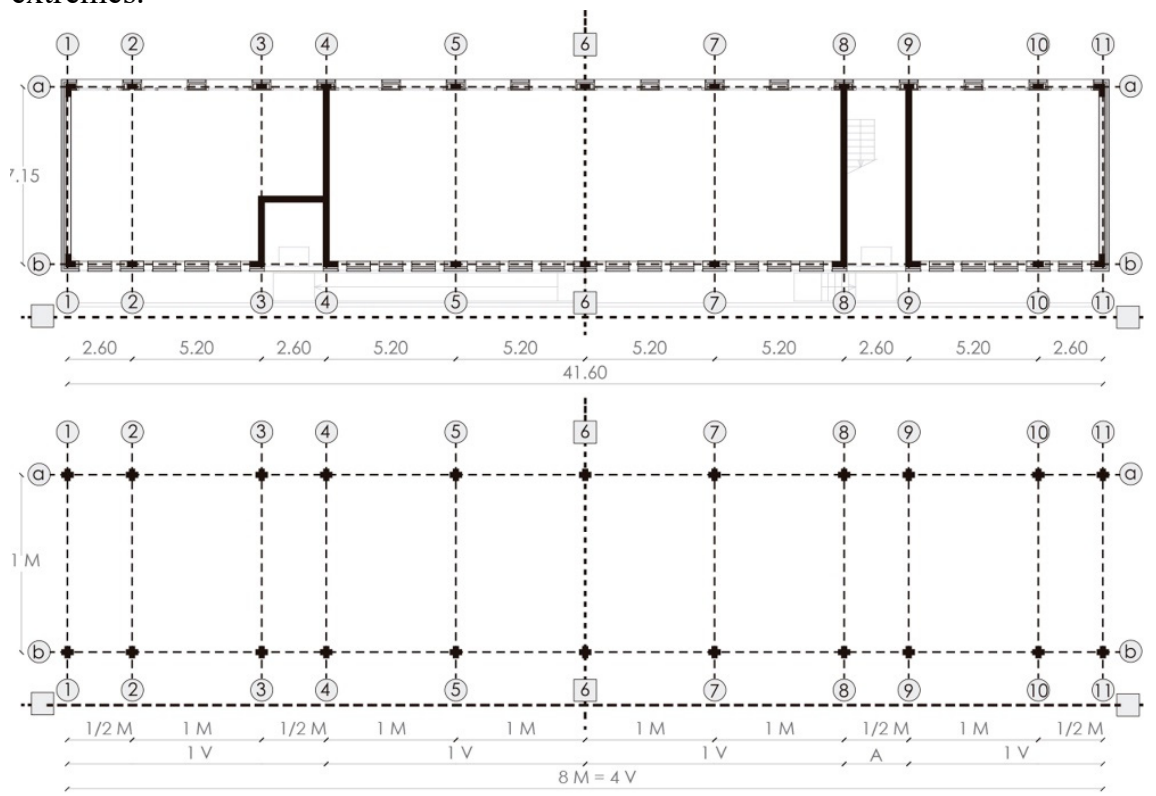

Figure 3: The structural unit in the typical floor plan.

As shown, the structural unit defines the size of the housing (four per floor formed by the size of two base units: $2 \mathrm{M}=\mathrm{V}$ ). Therefore, the organization of the housing units in the plan is determined by the structural grid: four housing units per floor, and eight structural modules. 


\subsection{The spatial unit}

Various units can be obtained from the grid made by the support axes. Some of the partitions are located along these axes and separate the spaces according to functional needs. The rest of the divisions are defined by the axes of the spatial layout. This shows the strong connection that exists between spatial and structural layouts. There is a main longitudinal axis allocated about $2 / 3$ between the main supports, separating two strips: a larger one with the served spaces such as living rooms and bedrooms, and on the other hand, the smaller strip with the servant spaces such as kitchens, bathrooms, laundry rooms, entrances and multifunctional spaces (Figure 4).

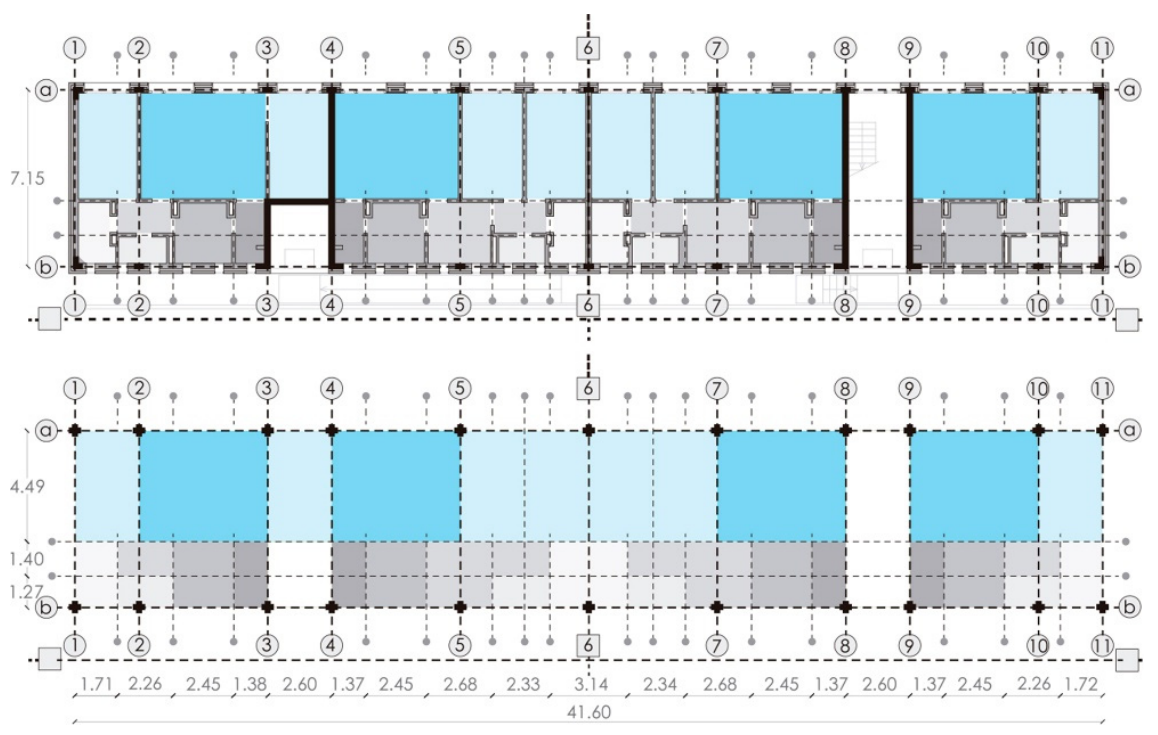

Figure 4: The spatial unit in the typical floor plan.

Some different degrees of spatiality can be observed, related to use and size. There are more spatial axes in the narrow strip as the rooms are smaller and secondary: those which have an occasional or servant function. The next level of higher occupancy and activity would be the kitchen, which is the largest space within the range of servant spaces.

And finally, we can analyse the served spaces strip, the larger within the plan. This strip is also divided into two: the main space for the living room, and the bedrooms, where the occupation and activity will be somewhat lower. Inside the narrow strip, the entrance and the bathrooms, with similar dimensions, are located opposite in the plan. Moreover, the multi-functional space and laundry are located together with the same dimensions.

The strict separation between served and servant spaces also helps to group the facilities all together in a core. This feature reduces structural costs, improves the quality of the facilities and reduces maintenance costs. "Distributor" spaces are 
used to connect the rooms, avoiding long corridors. They also allow the housing to be opened, creating the cross ventilation system.

The relationship between structure and space let us understand the connections between different base units and the advantage that it gives to the architect the use of symmetry and proportionality (Figure 5).

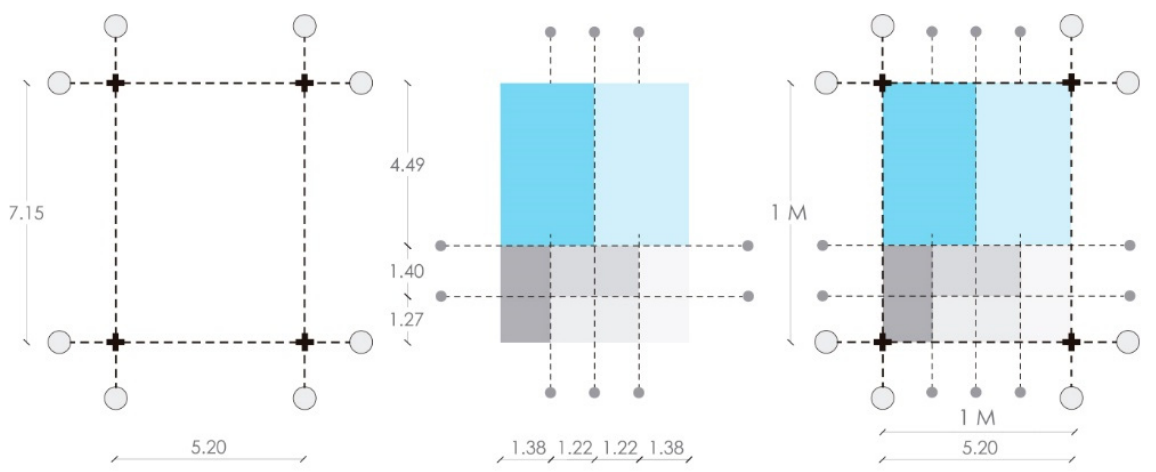

Figure 5: Structural and spatial units, and superposition of base units.

\subsection{The façade composition unit}

This composition unit consists of windows sizes and the distances between them. It is constructively based in the brick unit, but we cannot consider it separately from the previous ones, as they fit properly together in a perfectly defined relationship.

Seeking for this relationship, we take the structural separation of the base unit to the opposite access façades. We observe that by dividing this base unit, two perfectly fitted openings appear with equal distance between the supports axes. Across the façade a large rectangular window $(1.82 \mathrm{~m} \times 1.30 \mathrm{~m})$ provides natural light to the entrance. This compositional unit is formed by two openings in each structural unit per floor and it has the same dimensions. The access façade is formed by four smaller openings with dimensions of $0.36 \mathrm{~m} \times 0.36 \mathrm{~m}$. Here we find servant spaces, and therefore openings are reduced according to their function. The windows are arranged and dimensioned according to the open space, which reflects the spatial and compositional design approach.

As seen in Figure 6, a reticular net at both elevations is observed on the façade of the compositional unit. The perpendicular section of the façades by the axes of the main supports shows us the relationship between the openings and distances to the axes, a direct relationship between the structural and the compositional unit. By overlaying the two compositional units it is observed that the smaller windows are projected in the limits of the bigger windows, showing a clear and defined geometry (Figure 7). The order of the overlapping with the boundaries reinforces the idea of rationality and constructive efficiency. Furthermore, the compositional unit also controls the geometry of the brick that configures it. 


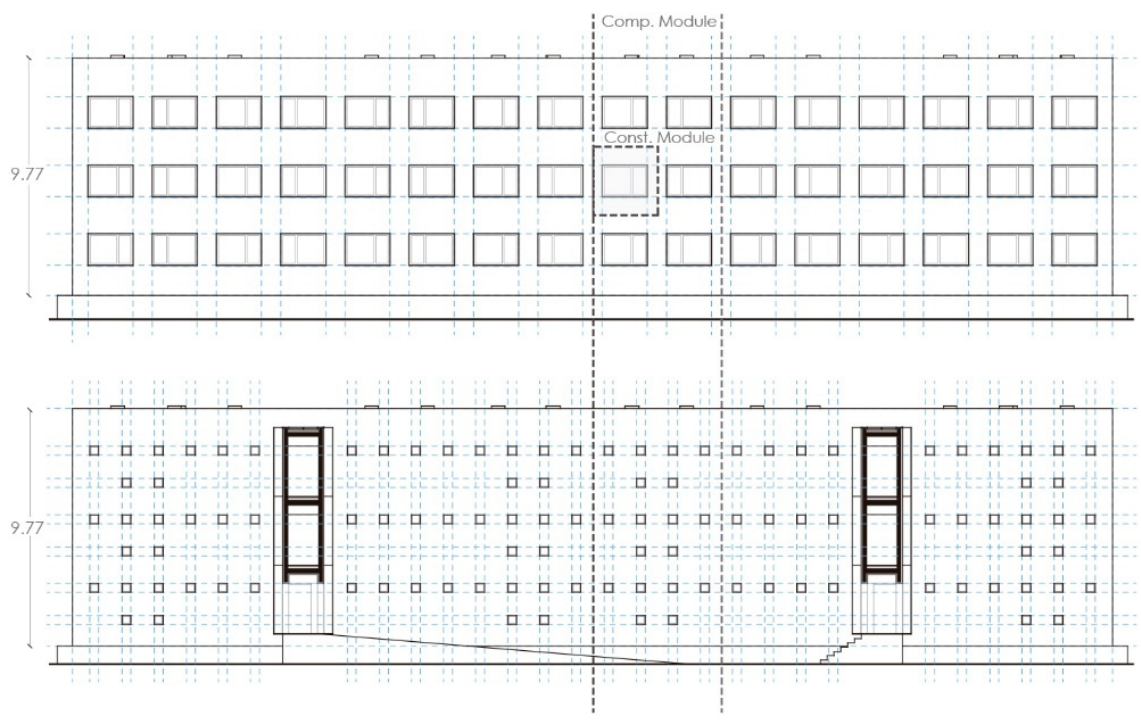

Figure 6: $\quad$ Compositional units on façades.
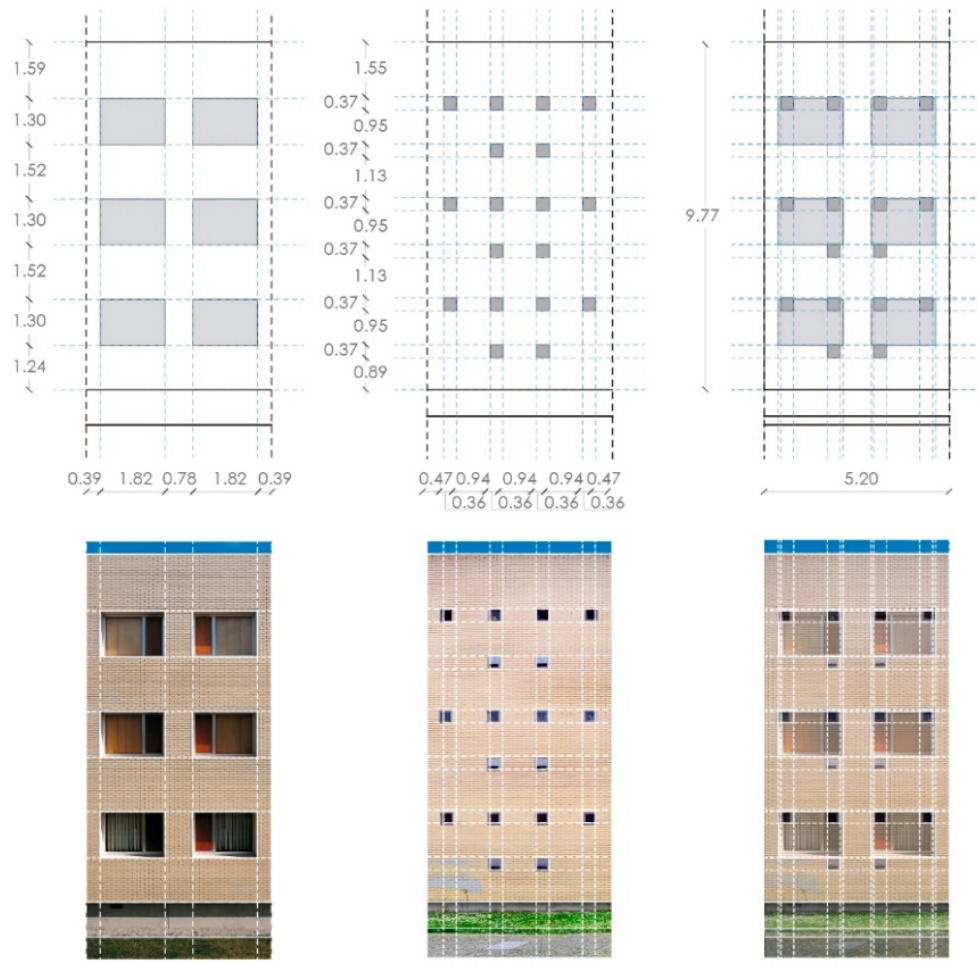

Figure 7: $\quad$ Superposition of compositional units. 
If we project intermediate axes in the middle of the separations of the openings within the boundaries of the unit, a perfect net is formed where the rows of brick fit together and the horizontal and vertical joints coincide with these axes. It is observed as in the project process that the dimensions of the brick are taken into account. They have a direct relationship with the composition of the openings and ultimately, with the whole configuration of the façades.

\subsection{The constructive unit}

The constructive unit completes the set of components of the modular design tool (Figure 8). Despite the budget constraints, a high level of quality is achieved thanks to the standardised construction solutions. If we take as an example the construction of the window unit type of the main façade, we can see a series of decisions that contribute reducing the costs.
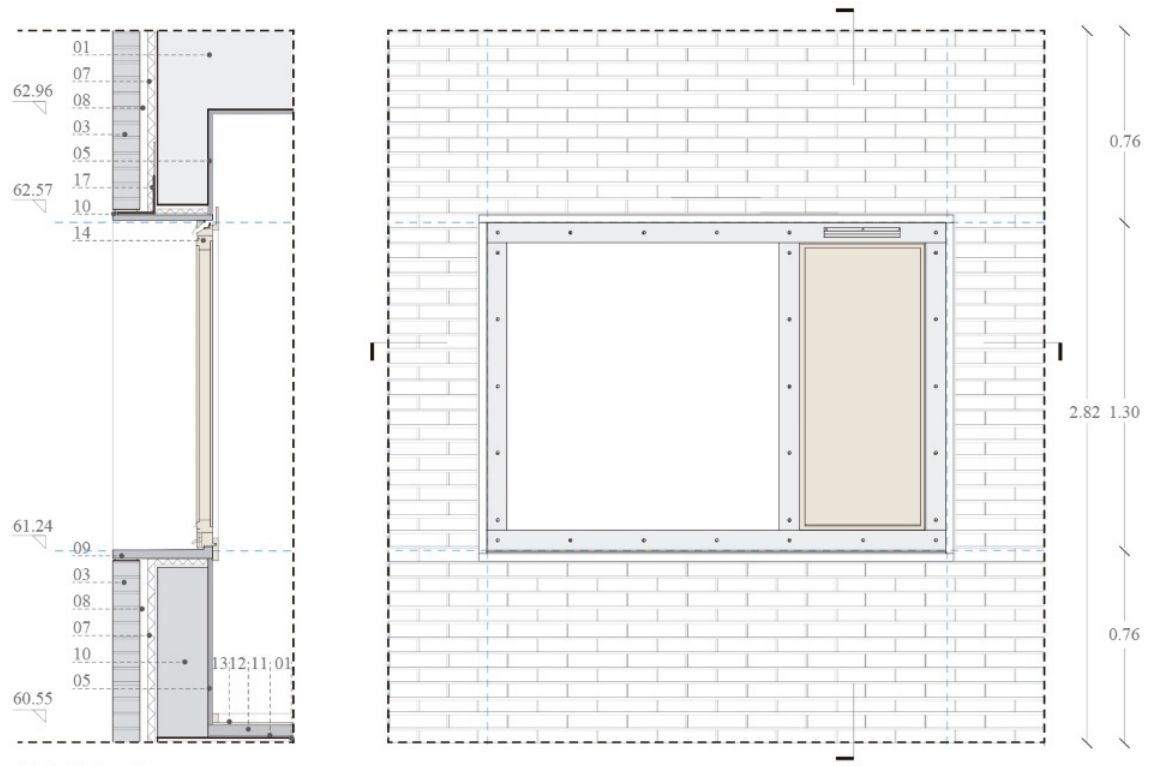

\section{Materials legend}

01 Reinforced concrete slab

02 Reinforced concrete support

03 Solid brick exterior wall

04 Brick wall

05 Insulation panel

06 Cement rendering

07 Cement plastering

08 Air chamber

09 Marble sill

10 Marble lintel

11 Insulation sheet

12 Leveling cement

13 Wood platform

14 Wood carpentry

15 Wood shutter

16 Glass

$17 \mathrm{~L}$ metal profile

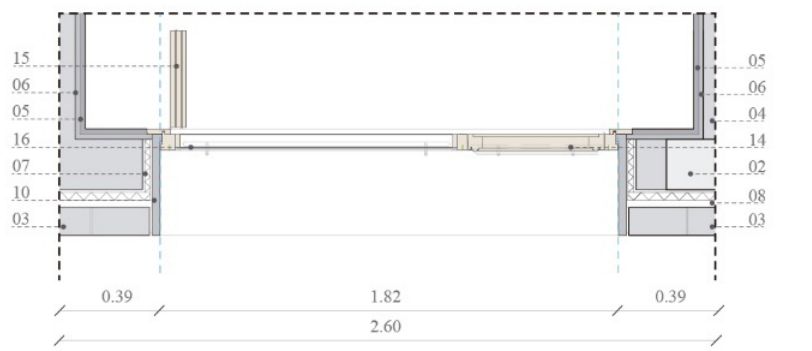

Figure 8: $\quad$ Constructive unit. 
Firstly, the functions of lighting and ventilation become independent in order to reduce the opening elements and simplify the relationships between them. The illumination is realised through a fixed glass of square proportion, whose size is adjusted to the lighting needs of the spaces, while the ventilation is controlled by an opaque wooden element. This reduces the number of joints, simplifies the carpentry and also enables the wooden shutters to be adjusted to size in order to keep sunlight out. The durability of the solution is guaranteed by the exterior metal gussets cover of the woodwork sections.

In short, a simple, accurate and rational detail that, just as the other units, contributes to create quality social housing.

\section{Corollary}

We would like to finish with an extract of the last interview given by João Álvaro Rocha in which the architect provides some insights about his relation to social housing throughout his career:

"The program of the social housing is like the single-family-house but complicated by ten. Because it has to be cheap, accessible, small; It must be constructively very effective; and beyond that, it is a program that from the 80s was somewhat forgotten, ignored. In some European countries it wasn't, they continued making a lot of public social housing, but here in Portugal we lost it a lot. And so, it became a kind of damn project that architects simply did not want to do. There were projects with low fees, gave a lot of work, work was never completed, they were degraded very quickly, everything was negative.

I was for some time thinking about it and came to the conclusion that it should be just the opposite; precisely because it had a social character it had a number of attributes that should be positive. One of the conclusions I reached was that most of the works were degraded because the exterior area was never completed, and the places chosen to place social housing were unskilled. So, I concluded that the problems of social housing were not problems themselves, but were due to the bad starting conditions.

Moreover, the attitude of the architects was not too correct and building companies made a lot of money with prefabrication, which disqualifies the building systems which were chosen exclusively on price rather than quality.

Then came the competition for social housing in Matosinhos that we won, and I think we did it because we faced the problem of social housing in a completely different way: it was realistic, inexpensive, with controlled costs, but we did things differently, it succeeded and was built... it took almost ten years but it was eventually built.

A number of requirements were considered, such as limiting the number of homes per block, or always have a number of community facilities accompanying the blocks. And also, my own requirement, which is the urban problem, the capacity of each intervention to generate, build the place, also appears, since that was precisely what I felt was absent in the 
social room. So, what mattered was that regardless of how the elevation was, was able to make territory, turn that into a recognisable place and qualified at the urban level. (...)

This gives a lot of work, because in the single-family home you project a window and there it is, while social housing it is necessary to project seven or eight windows before deciding which one is right, because of the costs, the building systems. It is demanding, but from my point of view is also the most fascinating aspect of these projects. (...)

My training is rossian, and therefore is closely linked to the typology; the typological study is fulfilled in depth. However, the problem of social housing is not the typological, this is the least we can demand an architect. There were other issues and problems that needed a more assertive response, especially in the beginning when we projected the competition for Matosinhos" [6].

As we have pointed out, the work of João Álvaro Rocha is an inexhaustible compendium of design tools for architects who have to deal with the design of social housing. It shows us how first-class social housing, with high quality finishes in spite of the reduced budgets, can be achieved by applying a limited number of design mechanisms with rigour and precision.

\section{References}

[1] Souto de Moura, E., João Álvaro Rocha em conversa com Eduardo Souto de Moura. Arquitectura Ibérica, 25, Caleidoscopio: Casal de Cambra, Portugal, pp. 159-166, 2008.

[2] Siza, A., Imaginar a evidência, Ediçoes 70: Lisboa, Portugal, p. 107, 1998.

[3] Rocha, J.A., Interview on the occasion of the prize for the social housing in Matosinhos year 2005: Architectural Prize Vale da Gãndara, given by Ordem dos Arquitectos, Four variations on housing, Domus, 987, 2015.

[4] Souto de Moura, E., Una conversación a propósito de la arquitectura, y de João Álvaro Rocha con Eduardo Souto de Moura. João Álvaro Rocha: Arquitectura 2002-2014, Tomo II, Equipamientos y Proyectos Urbanos, TC Cuadernos, Valencia, pp. 20-21, 2014.

[5] Pozo, J.M., Repetición en el proyecto Laboratorio Nacional de Investigación Veterinaria, João Álvaro Rocha-Arquitecturas de Autor, T6 Ediciones, p. 23, 2002.

[6] Extract of an unedited Interview to João Álvaro Rocha by Ricardo Merí de la Maza, Lugar da Varzea, Maia, recorded on 17 May 2014. 